\title{
SYNTHESIS OF DIVERSE TRACERS ON EWOD MICRODEVICE FOR POSITRON EMISSION TOMOGRAPHY (PET)
}

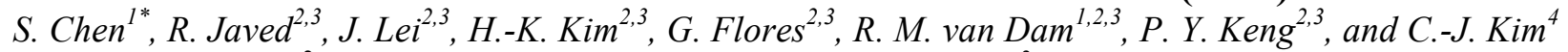 \\ ${ }^{1}$ Bioengineering Dept., ${ }^{2}$ Dept. of Molecular and Medical Pharmacology, ${ }^{3}$ Crump Institute for Molecular Imaging, \\ ${ }^{4}$ Mechanical and Aerospace Engineering Dept., University of California, Los Angeles (UCLA), California, U.S.A.
}

\section{ABSTRACT}

We demonstrate the synthesis of diverse tracers (sugar, DNA nucleoside, protein labeling compound, and neurotransmitter) using a single electrowetting-on-dielectric (EWOD) chip design with multifunctional electrodes for heating, temperature sensing, and EWOD driving. Furthermore, we present a key advantage of microfluidic chemical synthesis in increasing specific activity (radioactivity per mass of tracer) compared to macroscale synthesis. These are important steps toward more affordable, specific, and universal tracer production for use in positron emission tomography (PET).

\section{INTRODUCTION}

Positron emission tomography (PET) is a sensitive type of functional medical in vivo imaging for specific, quantitative, spatial, and temporal measurement of biochemical processes. Applications of PET include studying disease mechanisms, detecting early stage diseases, monitoring response to therapy, and developing therapeutics [1].

Since PET requires administration of a positron-emitting tracer with biological activity, availability of such tracers dictates ability to perform imaging. Over 1,600 PET tracers have been synthesized to date, but only several tracers are routinely available to imaging centers by commercial radiopharmacies [2]. Leveraging the radiopharmacies as a supply of radioisotope ( $\left[{ }^{18} \mathrm{~F}\right]$ fluoride) rather than tracers, and moving tracer production into the enduser's facility has potential to significantly increase diversity of tracers for the end user. Microfluidic tracer production could serve as the missing technological link by eliminating the need of the large capital investment involved in current PET probe production, (i.e. bulky synthesizers and expensive hot cells for radiation shielding).

After initial reports of synthesizing ${ }^{18} \mathrm{~F}$-labeled PET tracers with electrowetting-on-dielectric (EWOD) technology [3],[4], the digital microfluidic device has been used in conjunction with onchip radioactivity detection for optimizing microscale radiosynthesis conditions, and it has been demonstrated that its produced tracers have passed the numerous quality control requirements for human use [5]. While our earlier work demonstrated proof-of-concept radiosynthesis of $\left[{ }^{18} \mathrm{~F}\right]$ fluoro-2deoxy-D-glucose $\left(\left[{ }^{18} \mathrm{~F}\right] \mathrm{FDG}\right)[4]$ and $1-\left[{ }^{18} \mathrm{~F}\right]$ fluoro-4-nitrobenzene $\left(\left[{ }^{18} \mathrm{~F}\right] \mathrm{FNB}\right)[3]$, in this report we use one EWOD chip design and diversify synthesis to other PET tracers currently used in clinical and preclinical research: $\left[{ }^{18} \mathrm{~F}\right] \mathrm{FDG}$ (sugar), 3'-deoxy-3'$\left[{ }^{18} \mathrm{~F}\right]$ fluorothymidine $\left(\left[{ }^{18} \mathrm{~F}\right] \mathrm{FLT}\right.$, DNA nucleoside), tert-butyl 4$\left[{ }^{18} \mathrm{~F}\right]$ fluorobenzoate (the intermediate of $\left[{ }^{18} \mathrm{~F}\right] \mathrm{FSB}$, a prosthetic group for protein labeling), and $\left[{ }^{18} \mathrm{~F}\right]$ fallypride (neurotransmitter).

General aspects of microfluidics are attractive for tracer synthesis, because shorter reaction times result in less radioisotope decay and the small volumes match the nanogram amounts of tracer sufficient for PET imaging [6]. EWOD-based digital microfluidics has additional advantages in electronic control of droplet movement on a generic chip for easy reconfiguration to synthesize a variety of tracers. Our chip is also open to operate in air (i.e., no oil medium) without sidewalls, allowing rapid drying, evaporation, and solvent exchange; these are critical steps for many radiosynthesis processes that are water-sensitive but begin with cyclotron-produced $\left[{ }^{18} \mathrm{~F}\right]$ fluoride in $\left[{ }^{18} \mathrm{O}\right] \mathrm{H}_{2} \mathrm{O}$.

Furthermore, we present an important advantage of microfluidic radiosynthesis in increasing specific activity (radioactivity per mass of tracer). High specific activity is important in neurotransmitter tracers like $\left[{ }^{18} \mathrm{~F}\right]$ fallypride, where natural in vivo receptor quantities are low and easily saturated. Microfluidic synthesis should produce tracers with increased specific activity by reducing isotopic dilution and contamination from solvents, reagents, and transport lines [7]. We present the first experimental results comparing microfluidic synthesis with automated macroscale synthesis, demonstrating over 30 fold increase in specific activity when using the same reagents, concentrations, and heating times.

\section{DEVICE AND MATERIALS \\ EWOD Device Fabrication}

Our EWOD device has six inlets and droplet pathways that meet at a circular reaction site (Figure 1). The reaction site consists of 4 concentric multifunctional electrodes, each a resistive element that can be used for EWOD actuation of droplets or feedbackcontrolled heating. This multi-element reaction site can center the droplet and maintain temperature more uniformly than a singleelement heater as the droplet shrinks during evaporations [4].

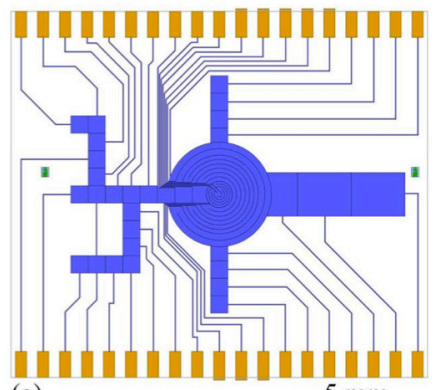

(a)
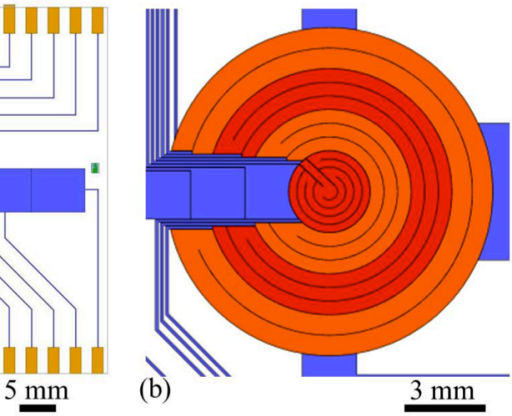

Figure 1: EWOD chip design for tracer synthesis. (a) device layout with multifunctional ITO electrodes (blue) and gold contacts (yellow), (b) the reaction site zoomed to show the individually controlled 4 concentric resistive heating rings.

EWOD chips and cover plates were fabricated from $700 \mu \mathrm{m}$ thick glass wafers coated with $140 \mathrm{~nm}$ ITO (Semiconductor Solutions). $\mathrm{Cr}(20 \mathrm{~nm})$ and $\mathrm{Au}(200 \mathrm{~nm})$ were evaporated onto the wafers. $\mathrm{Au}, \mathrm{Cr}$, and ITO layers were etched to form EWOD electrodes, heaters, connection lines, and contact pads. PECVD silicon nitride $(2 \mu \mathrm{m})$ was deposited as a dielectric on the device plate, and a thinner layer $(100 \mathrm{~nm})$ was deposited on the cover plate. Teflon ${ }^{\circledR}(250 \mathrm{~nm})$ was spin-coated and annealed at $340^{\circ} \mathrm{C}$ under vacuum to make the surfaces hydrophobic.

Test slides for testing reaction conditions were made from 25 x $25 \times 1 \mathrm{~mm}$ glass microscope slides (Corning), on to which 250 $\mathrm{nm}$ Teflon ${ }^{\circledR}$ was spin-coated and annealed at $340^{\circ} \mathrm{C}$.

\section{Device Actuation}

EWOD actuation voltage for droplet movement was generated from a $10 \mathrm{kHz}$ signal (33220A waveform generator, 
Agilent Technologies) amplified to 100 Vrms (Model 601C, Trek). The voltage was applied selectively to desired electrodes for droplet movement by individually addressable relays (AQW610EH PhotoMOS relay, Panasonic) that were controlled by a LabVIEW program using a digital I/O device (NI USB-6509, National Instruments).

A second digital I/O device (NI USB-6250, National Instruments) was used to control a multichannel heater driver that was designed and built in house to measure and maintain feedbackcontrolled temperatures over the chip's four individual resistive heaters. Each chip's multifunctional electrodes were individually connected to a switch to alternate between EWOD actuation voltage or temperature measurement and heating.

To test reaction conditions with the Teflon ${ }^{\circledR}$ coated glass slides, a Peltier module (Model 5R7-001, McShane) was used for temperature control.

\section{Macroscale Radiosynthesizer}

Automated Radiochemistry Platform (ARC-P) was used for conventional synthesis of $\left[{ }^{18} \mathrm{~F}\right] \mathrm{FDG}$ to compare specific activity with microfluidic synthesis [8]. ARC-P is a semi-automated inhouse macroscale synthesizer with high temperature, high pressure, and multi-pot capabilities.

\section{Solution Preparation}

Anhydrous acetonitrile ( $\mathrm{MeCN}, 99.8 \%)$, anhydrous dimethyl sulfoxide (DMSO, 99.9\%), anhydrous methanol (MeOH, 99.8\%), $\mathrm{O}$-( $N$-succinimidyl)- $N, N, N^{\prime}, N^{\prime}$-tetramethyluronium tetrafluoroborate (TSTU, 98\%), 2,3-dimethyl-2-butanol (thexyl alcohol), potassium carbonate $\left(\mathrm{K}_{2} \mathrm{CO}_{3}, 99 \%\right), 4,7,13,16,21,24$-hexaoxa1,10-diazobicyclo (8.8.8)-hexacosane ( $\mathrm{K}$ 2.2.2, 98\%), and mannose triflate (FDG precursor) were purchased from SigmaAldrich. $1 \mathrm{~N} \mathrm{HCl}$ (certified, Fisher Chemicals) was purchased from Fisher Scientific. Tetrabutylammonium bicarbonate $\left(\mathrm{TBAHCO}_{3}\right)$, 3-N-Boc-5'-O-dimethoxytrityl-3'-O-nosyl-thymidinie

(FLT precursor), 4-(tert-butoxycarbonyl)-trimethylbenzeneammonium triflate (tert-butyl 4-fluorobenzoate precursor), and tosyl-fallypride (fallypride precursor) were purchased from ABX Advanced Biochemical Compounds (Radeberg, Germany) and used as received.

No-carrier-added $\left[{ }^{18} \mathrm{~F}\right]$ fluoride ion was obtained from the UCLA Crump Institute for Molecular Imaging Cyclotron and Radiochemistry Technology Center by irradiation of $97 \%{ }^{18} \mathrm{O}$ enriched water with an $11 \mathrm{MeV}$ proton beam using an RDS-112 cyclotron (Siemens).

\section{RESULTS AND DISCUSSION}

Macroscale and microscale specific activity comparison

Specific activity is the radioactivity per total mass of tracer compound $\left({ }^{18} \mathrm{~F}\right.$-labeled and ${ }^{19} \mathrm{~F}$-labeled $)$. Nonradioactive $\left({ }^{19} \mathrm{~F}\right.$ labeled) molecules compete with radioactive $\left({ }^{18} \mathrm{~F}\right.$-labeled) ones for binding or uptake, resulting in lower imaging signal strength and lower contrast. High specific activity has added importance in neural imaging where receptors quantities are low and easily saturated. This is especially significant where the numbers of receptors is extremely small in the brain of small animals [9].

Microfluidic radiosynthesis can be beneficial to increase specific activity because greater mass and heat transfer result in shorter reaction times and allow less radioisotope decay. Also, reduced volumes are hypothesized to reduce contamination by nonradioactive fluorine-19 from solvents and reagents [7].

We compared specific activity of microfluidic synthesis with that of conventional synthesis by producing $\left[{ }^{18} \mathrm{~F}\right] \mathrm{FDG}$ simultaneously with an EWOD device and also an ARC-P macroscale radiosynthesier from the same batch of $\left[{ }^{18} \mathrm{~F}\right]$ fluoride. The synthesis process on EWOD device has been described by Keng et al. [5]. The same reagent sources were used for both synthesizers, but the macroscale synthesis used 80 times more reagents.

Product from each synthesizer was extracted and passed through a purification cartridge. After the final $\left[{ }^{18} \mathrm{~F}\right] \mathrm{FDG}$ product was eluted, its radioactivity was measured with a dose calibrator (CRC-25 PET, Capintec) and its radiochemical purity was evaluated using radio-TLC (MiniGITA star, Raytest). After overnight radiodecay, concentration and mass of the tracer was measured by UV absorbance and an analytical balance.

EWOD synthesis had over 30 fold increase in specific activity compared to automated macroscale synthesis, when using the same reagents, concentrations, and heating times (Table 1).

Table 1: $\left.{ }^{18} F\right] F D G$ was produced in parallel by an EWOD device and automated macroscale system using the same reagent sources and procedure (except for 80x increase in macroscale synthesis reagent volumes). Specific activity of radiotracers produced by EWOD showed 34.5 fold average increase.

\begin{tabular}{|c|c|c|c|}
\hline & \multicolumn{2}{|c|}{ 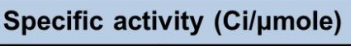 } & \multirow{2}{*}{ Improvement Ratio } \\
\hline & EWOD & Macroscale & \\
\hline Exp 1 & 0.74 & 0.014 & 55.0 \\
\hline Exp 2 & 2.86 & 0.091 & 31.4 \\
\hline Average & 1.80 & 0.052 & 34.5 \\
\hline
\end{tabular}

\section{Reaction condition optimization}

Different volumes, concentrations, and temperatures were used for each tracer synthesis after conditions had been optimized for microscale reactions on a Teflon-coated glass substrate, which mimics an EWOD chip (Figure 2). Herein we adapted the bulky alcohol method to $\left[{ }^{18} \mathrm{~F}\right] \mathrm{FLT}$ and $\left[{ }^{18} \mathrm{~F}\right]$ fallypride synthesis on EWOD to assist the nucleophilic fluorination reactions [10]. The protic solvent enabled high radiofluorination efficiencies (80-85\%) at lower temperature $\left(100{ }^{\circ} \mathrm{C}\right)$; in comparison, the conventional method requires higher temperatures $\left(130-180{ }^{\circ} \mathrm{C}\right)$ to achieve comparable fluorination efficiencies.

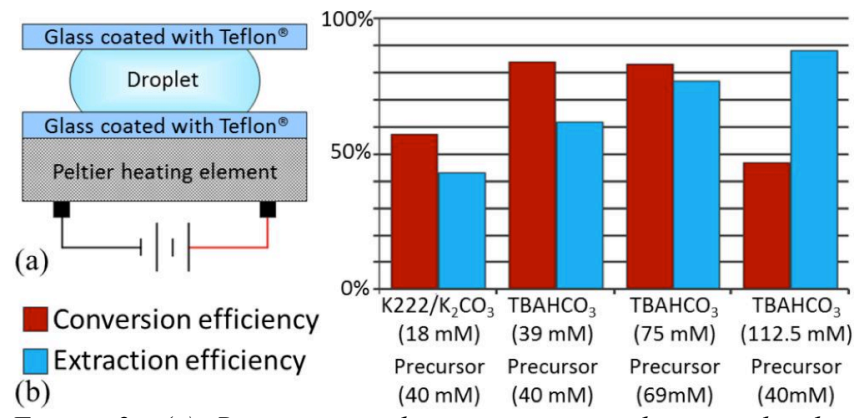

Figure 2: (a) Reaction conditions were tested using droplets sandwiched between glass coated with Teflon ${ }^{\circledR}$ and heated by a Peltier element. This can be done more intensively with the EWOD chip. (b) Data showing improved $\left[{ }^{18} F\right] F L T$ fluorination efficiency with different concentrations of tetrabutylammonium bicarbonate ( $\mathrm{TBAHCO}_{3}$ ) and the FLT precursor.

\section{Synthesis of 3'-deoxy-3' $-\left[{ }^{18}\right.$ F $]$ fluorothymidine $\left(\left[{ }^{18}\right.\right.$ F $]$ FLT $)$}

$\left[{ }^{18} \mathrm{~F}\right] \mathrm{FDG}$ is the most widely used PET tracer with applications in oncologic, neurological, and cardiac imaging; but it is not target-specific, which can lead to false positives due to unrelated natural causes of increased glucose uptake and glycolysis like inflammation and muscle activity, and has high background in 
areas such as the heart, brain, and the vicinity of the bladder. $\left[{ }^{18} \mathrm{~F}\right] \mathrm{FLT}$, a DNA nucleoside analog of thymidine, is used to estimate cell proliferation, in many cases a more specific hallmark of malignant tumors.

The two-step reaction is illustrated in Figure 3. The first step is the fluorination reaction in which FLT precursor, 3-N-Boc-5'-Odimethoxytrityl-3'-O-nosyl-thymidinie, is labeled with activated $\left[{ }^{18} \mathrm{~F}\right]$ fluoride to produce the fluorinated intermediate, 3-N-Boc-5'O-dimethyltrityl-3'-deoxy-3'fluorothymidine. The second step is the hydrolysis reaction using $\mathrm{HCl}$ to remove the dimethoxytrityl and the tert-butoxycarbonyl protecting groups.
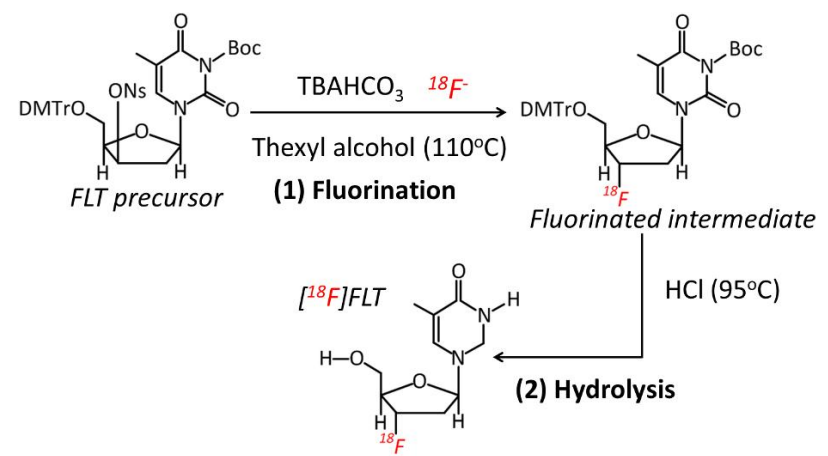

Figure 3: Two-step synthesis of $\Gamma^{18}$ FlFLT.

The multistep $\left[{ }^{18} \mathrm{~F}\right] \mathrm{FLT}$ synthesis was performed on EWOD: first, $3 \mu \mathrm{L}$ of the $\left[{ }^{18} \mathrm{~F}\right]$ fluoride mixture is pipetted onto the EWOD chip through a dedicated loading site on the cover plate edge and transported to the heater by EWOD actuation. This loading process is repeated an additional time. The $6 \mu \mathrm{L}\left[{ }^{18} \mathrm{~F}\right]$ fluoride mixture is heated to $105{ }^{\circ} \mathrm{C}$ for 1 minutes to evaporate the solvent. The $\left[{ }^{18} \mathrm{~F}\right]$ fluoride mixture is dried via azeotropic distillation by transporting three $\mathrm{MeCN}$ droplets $(3 \mu \mathrm{L}$ each) through the first loading edge into the heater site and heating at $105{ }^{\circ} \mathrm{C}$ for 1 minute. This drying step is repeated one additional time.

For the fluorination reaction, $4 \mu \mathrm{L}$ of FLT precursor in thexyl alcohol $(2 \mu \mathrm{L} ; 45 \mathrm{mM})$ and $4 \mu \mathrm{L}$ of $\mathrm{MeCN}$ are pipetted onto the EWOD chip through the second loading edge to avoid crosscontamination. The droplets are moved to the dried $\left[{ }^{18} \mathrm{~F}\right]$ fluoride residue on the heating site by electrowetting, and the reaction droplet is heated at $110^{\circ} \mathrm{C}$ for 5 minutes.

For the deprotection step, $2.5 \mu \mathrm{L}$ of $\mathrm{HCl}(1 \mathrm{~N})$ and $2.5 \mu \mathrm{L}$ of $\mathrm{MeCN}$ are added and transported to the heater region to perform the hydrolysis reaction. The reaction droplet is heated at $95{ }^{\circ} \mathrm{C}$ for 5 mins. After the synthesis, the cover plate is removed and the crude $\left[{ }^{18} \mathrm{~F}\right] \mathrm{FDG}$ product is extracted by pipette using $25 \mu \mathrm{L}$ of $\mathrm{MeCN} \mathrm{H}_{2} \mathrm{O}$ and $100 \mu \mathrm{L}$ of $\mathrm{H}_{2} \mathrm{O}$.

The product is then confirmed with high performance liquid

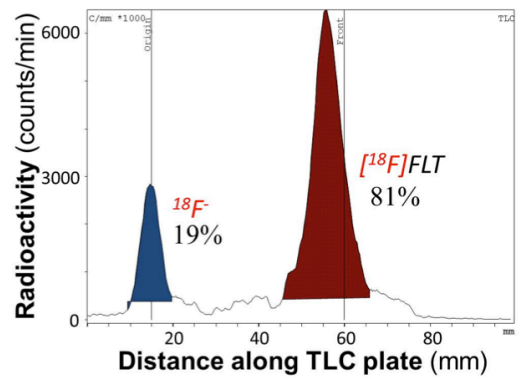

Figure 4: Radio-TLC analysis to determine radiofluorination efficiency of $\left[^{18} \mathrm{~F}\right] F L T$. chromatography (HPLC) and analyzed with radio-thin layer chromatography (TLC) (Figure 4). Fluorination yield on EWOD was measured to be $81 \% \pm 1 \%(n=4)$.

\section{Synthesis of tert-butyl $4-\left[{ }^{18}\right.$ F]fluorobenzoate}

Tert-butyl 4- $\left[{ }^{18} \mathrm{~F}\right]$ fluorobenzoate is the fluorinated intermediate of N-succinimidyl-4- $\left[{ }^{18} \mathrm{~F}\right]$ fluorobenzate ( $\left.\left[{ }^{18} \mathrm{~F}\right] \mathrm{SFB}\right)$, a prosthetic agent for radiolabeling antibodies and other biomolecules that are sensitive to harsh reaction conditions (temperature, solvents, $\mathrm{pH}$ ). The three-step synthesis of $\left[{ }^{18} \mathrm{~F}\right] \mathrm{SFB}$ is illustrated in Figure 5. The first step is the aromatic nucleophilic fluorination of the 4-(tert-butoxycarbonyl)-trimethylbenzene ammonium triflate (SFB precursor), which involved harsher reaction conditions in comparison to aliphatic fluorination reactions. The second step is a hydrolysis reaction using trifluoroacetic acid to hydrolyze the t-butyl ester. The third step for final product conversion is TSTU activation.

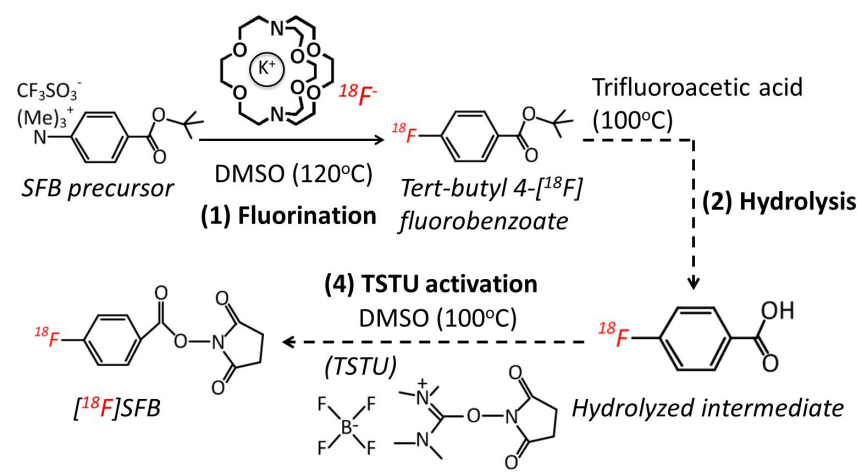

Figure 5: Three-step synthesis of $\left[{ }^{18} \mathrm{~F}\right] \mathrm{SFB}$.

For tert-butyl $4-\left[{ }^{18} \mathrm{~F}\right]$ fluorobenzoate synthesis on EWOD, 3 $\mu \mathrm{L}$ of $\left[{ }^{18} \mathrm{~F}\right]$ fluoride mixture pipetted onto the EWOD chip and moved by electrowetting to the heater. The solvent is evaporated at $105{ }^{\circ} \mathrm{C}$ for 1 minute. Two azeotropic drying steps are then performed in which $9 \mu \mathrm{L}$ of $\mathrm{MeCN}$ are added to the residue site and heated at $105{ }^{\circ} \mathrm{C}$ for 1 minute. For fluorination, $6 \mu \mathrm{L}$ of the SFB precursor dissolved in DMSO was loaded to the chip and heated at $120{ }^{\circ} \mathrm{C}$ for 12 minutes.

The reaction droplet was extracted and analyzed by HPLC and radio-TLC. Fluorination yield on EWOD was measured to be $83 \%+11 \%(n=4)$.

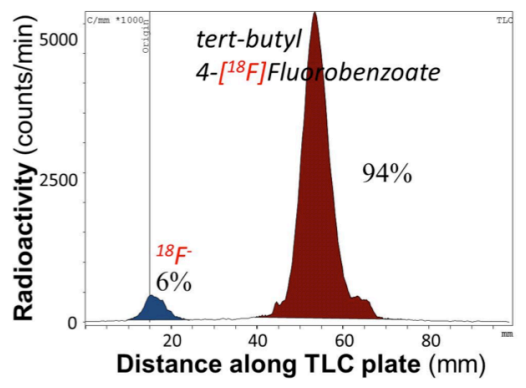

Figure 6: Radio-TLC analysis to determine radiofluorination efficiency of $\left[{ }^{18} \mathrm{~F}\right]$ tert-butyl $4-\left[{ }^{18} \mathrm{~F}\right]$ fluorobenzoate.

Synthesis of $\left[{ }^{18} \mathrm{~F}\right]$ fallypride

$\left[{ }^{18} \mathrm{~F}\right]$ fallypride is a dopamine receptor antagonist, useful for studying Alzheimer's and Parkinson's disease. $\left[{ }^{18} \mathrm{~F}\right] \mathrm{SFB}$ and $\left[{ }^{18} \mathrm{~F}\right]$ fallypride are not commercially available despite their proven effectiveness. $\left[{ }^{18} \mathrm{~F}\right]$ fallypride is synthesized by a single-step fluorination reaction as shown in Figure 7.

For this synthesis on EWOD, $7 \mu \mathrm{L}$ of $\left[{ }^{18} \mathrm{~F}\right]$ fluoride mixture 


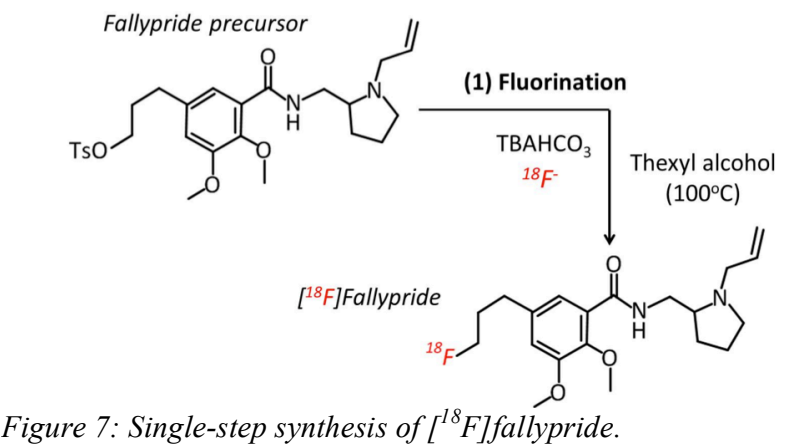

was pipetted onto the chip, moved to the heater by EWOD actuation, and heated at $105{ }^{\circ} \mathrm{C}$ for $1 \mathrm{~min}$. Azeotropic drying was performed twice by adding $12 \mu \mathrm{L}$ of $\mathrm{MeCN}$ and heating at $105^{\circ} \mathrm{C}$ for $1 \mathrm{~min}$. For fluorination, $2 \mu \mathrm{L}$ of FLT precursor and $6 \mu \mathrm{L}$ of $\mathrm{MeCN}$ were added and heated at $100{ }^{\circ} \mathrm{C}$ for 7 minutes. After extraction and analysis, $\left[{ }^{18} \mathrm{~F}\right]$ fallypride fluorination yield was measured to be $82 \% \pm 9 \%(n=3)$.

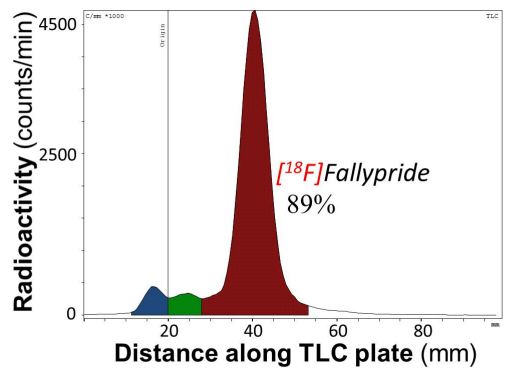

Figure 9: Radio-TLC analysis to determine radiofluorination efficiency of $\left[{ }^{18} \mathrm{~F}\right]$ fallypride.

\section{CONCLUSION}

We have demonstrated the synthesis of diverse tracers from cyclotron-produced $\left[{ }^{18} \mathrm{~F}\right]$ fluoride solutions using one design of an EWOD device with multifunctional electrodes for heating. All 4 radiolabeled compounds have been reliably synthesized on EWOD chip with conversion efficiencies between $70-90 \%$, comparable to or greater than those of commercially available macroscale commercial synthesizers (Table 2). In addition to aliphatic nucleophilic fluorination reactions, we have also demonstrated aromatic nucleophilic fluorination, which generally requires harsher reaction conditions. This success indicates the final goal

Table 2: Four diverse radiolabeled molecules synthesized by EWOD with the same chip design.

\begin{tabular}{|c|c|c|c|c|c|}
\hline Tracer & Molecule & Application & $\begin{array}{c}\text { Radiopharmacy } \\
\text { availability }\end{array}$ & \begin{tabular}{|c|}
$\begin{array}{c}\text { Fluorination } \\
\text { yield } \\
\text { (on EWOD) }\end{array}$ \\
\end{tabular} & $\begin{array}{l}\text { Hydrolysis } \\
\text { yield } \\
\text { (on EWOD) } \\
\end{array}$ \\
\hline $\begin{array}{c}\Gamma^{18} \text { Flfluoro-2- } \\
\text { deoxy-D-glucose } \\
\left(I^{18} F \mid F D G\right)\end{array}$ & HOS & $\begin{array}{c}\text { Sugar } \\
\text { metabolism }\end{array}$ & Yes & $\begin{array}{c}89 \% \pm 9 \% \\
(n=3)\end{array}$ & $\begin{array}{c}97 \% \pm 3 \% \\
(n=3)\end{array}$ \\
\hline $\begin{array}{c}3^{\prime} \text {-deoxy- } 3^{\prime}-I^{8} \mathrm{FJ} \\
\text { fluorothymidine } \\
\left(I^{18} \mathrm{~F} / \mathrm{FLT}\right)\end{array}$ & & $\begin{array}{c}\text { DNA } \\
\text { proliferation }\end{array}$ & Limited & $\begin{array}{c}81 \% \pm 1 \% \\
(n=4)\end{array}$ & $\begin{array}{c}100 \% \pm 0 \% \\
(\mathrm{n}=4)\end{array}$ \\
\hline $\begin{array}{l}\left.\text { tert-butyl } 4-\Gamma^{18} \mathrm{~F}\right] \\
\text { fluorobenzoate }\end{array}$ & & $\begin{array}{l}\text { Protein } \\
\text { labeling }\end{array}$ & No & $\begin{array}{c}83 \% \pm 11 \% \\
(n=4)\end{array}$ & (not applicable) \\
\hline${ }^{18}$ Flfallypride & & $\begin{array}{c}\text { Neural } \\
\text { transmitter } \\
\text { binding }\end{array}$ & No & $\begin{array}{c}82 \% \pm 9 \% \\
(n=3)\end{array}$ & (not applicable) \\
\hline & & & & & \\
\hline
\end{tabular}

of an affordable, reliable, and flexible synthesizer, which would empower final users to produce tracers of their choice locally, is reachable in the foreseeable future.

We have shown that EWOD-based digital microfluidic reactions can carry out high-yield chemical reactions, and provided evidence of an additional advantage in increased specific activity of the tracers. We will investigate EWOD device geometry further to understand the factors that influence specific activity and develop a more generic synthesizer EWOD chip for increased specific activity. The efficacy of the synthesized PET tracers will be demonstrated by use in small animal preclinical imaging.

\section{ACKNOWLEDGEMENT}

This work was supported in part by the UCLA Foundation from a donation made by Ralph \& Marjorie Crump for the UCLA Crump Institute for Molecular Imaging and the Department of Energy [DE-SC0005056]. We thank Prof. David Stout for use of radiolabeling facilities, Dr. Gaurav Shah for initial demonstration of the EWOD compatibility with typical radiochemistry solvents, Dr. Wyatt Nelson for developing the multi-functional EWOD electrodes, and Dr. Saman Sadeghi and Bob Silverman for developing the multi-channel temperature controller and software.

\section{REFERENCES}

[1] M.E. Phelps, "Positron emission tomography provides molecular imaging of biological processes", Proc. National Academy of Science, 97, 9226-9233, (2000).

[2] R. Iwata, Reference book for PET radiopharmaceuticals, CYRIC, Tohoku University, Sendai, Japan, 2004.

[3] S. Chen, H. Ding, G.J. Shah, R.M. van Dam, and C.-J. Kim, "EWOD microdevices for synthesis of ${ }^{18} \mathrm{~F}$-labeled tracers for positron emission tomography (PET)", Tech. Dig. Solid-State Sensor and Actuator Workshop, Hilton Head Island, SC, 6/66/10, Transducer Research Foundation, (2010), pp. 37-40.

[4] S. Chen, P.Y. Keng, G.J. Shah, R.M. van Dam, and C.-J. Kim, "Synthesis of ${ }^{18} \mathrm{~F}$-labeled probes on EWOD platform for positron emission tomography (PET) preclinical imaging", Proc' Int. Conf. MEMS, Cancun, Mexico, 1/23-1/27, IEEE, (2011), pp. 980-983.

[5] P.Y. Keng, S. Chen, H. Ding, S. Sadeghi, G.J. Shah, A. Dooraghi, M.E. Phelps, N. Satyamurthy, A.F. Chatziioannou, C.J. Kim, and R.M. van Dam, "Micro-chemical synthesis of molecular probes on an electronic microfluidic device", Proc. National Academy of Science, 109, 3, 690-695, (2012).

[6] A.M. Elizarov, "Microreactors for radiopharmaceutical synthesis", Lab Chip, 9, 10, 1326-1333 (2009).

[7] R. Bejot, A.M. Elizarov, E. Ball, J. Zhang, R. Miraghaie, H.C. Kolb, and V. Gouverneur, "Batch-mode microfluidic radiosynthesis of $\mathrm{N}$-succinimidyl-4-[ $\left.{ }^{18} \mathrm{~F}\right]$ fluorobenzoate for protein labeling", J Label Compd. Radiopharm, 54, 3, 117-122 (2011).

[8] M.A. Eddings, S. Olma, M. Wang, Y. Deng, H. Ding, N. Satyamurthy, K. Shen, and R.M. van Dam, "Automated Radiochemistry Platform (ARC-P): plug-and-play radiochemistry modules for reconfigurable radiosynthesis," Int. Symp. Radiopharmaceutical Sciences, Edmonton, Canada, 7/12, Society of Radiopharmaceutical Sciences (2009), poster.

[9] M.P. Kung and H.F. Kung, "Mass effect of injected dose in small rodent imaging by SPECT and PET," Nuclear Medicine and Biology, 32, 7, 673-678, (2005).

[10] B.S. Moon, J.H. Park, H.J. Lee, J.S. Kim, H.S. Kil, B.S. Lee, D.Y. Chi, B.C. Lee, Y.K. Kim, and S.E. Kim, "Highly efficient production of $\left[{ }^{18} \mathrm{~F}\right]$ fallypride using small amounts of base concentration," Applied Radiation and Isotopes, 68, 12, 22792284 (2010).

\section{CONTACT:}

*Supin Chen, tel: +1-310-825-3977; supin.chen@engineering.ucla.edu 